\section{Preventation of Deformity}

Reprinted by kind permission of "The British Journal of Physical Medicine."

A great deal of time and ingenuity are being expended at present on devices to assist disabled (or partially disabled) persons to live and work in a semblance of normality, in spite of their handicaps. Such devices range from specially constructed sticks and crutches to slinging for paralysed arms, and from wheel-chairs to tongs to pull up one's stockings. These efforts are most useful and valuable and should certainly not be discouraged, for they may transform a helpless cripple into a comparatively independent member of the community.

What we should, however, be glad to know is whether a comparable amount of time, care and ingenuity are being devoted to the prevention of deformities and disabilities. There is considerable danger of the development of what Dr. Francis Bach has called a "wheel-chair mentality" in relation to chronic or acute disease of a potentially crippling nature. After all, any case in which elaborate devices for overcoming deformities are necessary, represents, in some degree, a failure of treatment. It is supremely important to tackle the problem as soon as it begins to arise, remembering (as Dr. Hugh Burt told the World Congress for Physical Therapy) that much deformity is preventable.

Prevention of deformity and preservation of function can hardly be divided, but it sometimes becomes necessary to put certain limits on function in order to prevent deformity. Part of the limitation will be quantitative and part of it qualitative. It might, perhaps, be said that quantitative limitation is most important in early rheumatoid arthritis, when rest is indicated. Such movement as is allowed should, however, be carried out in the best possible approach to normality. A few movements in the full range of a joint may be better than a large number in a restricted range.

There are, nevertheless, some uses of the hands that may have to be restricted or excluded because they, more than others, tend to encourage deformity. Take, for example, ulnar deviation in rheumatoid arthritis, studies of which have recently been made by Vaino and Oka (1953) and by Baker (1953). In the former article the suggestion is made that this deformity is commoner in women because they go on working whereas men take sick leave. That is a broad generalization which tells only part of the truth. Not only do women continue to work, but many of their occupations tend to be carried out in a position which encourages the deformity. A particularly important example is knitting, especially if done with the postures and movements used in Great Britain. Yet very many women go on knitting when it is quite unsuitable occupation for them. Another example, affecting both sexes, is walking with the use of an ordinary crook-handled stick. In cases in which the feet and knees are affected first, it is a matter of speculation how far the subsequent evolution in the hands is influenced by grasping a stick, so that much of the weight of the body is taken on the hand in that deviated position of the fingers.

The answer to the questions raised can be found only by detailed studies of -posture and motion, which ought to be undertaken and pursued with vigour and precision.

Baker, Frances (1953). Arch. phys. Med., 34, 299.

Vaino, K., and Oka, M. (1953). Anh. rheum. Dis., 12, 123.

\section{Curvature of the Spine}

In out-patient departments, panel doctors'. waiting-rooms, mothers' meetings or anywhere else where men and women gather together and talk, one may hear some remarkable reported diagnoses. Many of them rest on misheard medical terms, and probably convey little or nothing to the people who hear or repeat them, but there are two very common mis-descriptions, often to be heard from the lips of people who should know better, and which must imply a total ignorance of physiology and anatomy. One is that the patient or some friend is suffering from blood pressure, the other that the affliction is spinal curvature. It would probably surprise some of these glib repeaters of misunderstood phrases to be told that they would die in the absence of the first and be unable to stand or walk without the second.

The curvatures of the spine are, indeed, one of the marvels of creation, or rather of evolution. They begin to be so in animals which still go on four legs. It is one thing for a head the size of a hen's or a weasel's to be supported in advance of the spine, but when we come to the relative proportions of head and back in a lion, a horse or a dog, the wonder grows. In these higher mammals the main curves of the spine varythe horse, for example, has much more marked spinal curvatures than has the cow, but if one puts a human being on all fours or makes a dog stand on its hind legs the comparison between the human and the animal spine is easy to make, and the likeness between the shoulder and hip joints and those of the fore and hind limbs is also considerable. In the monkey-house the gradual changes which enabled the upright posture to be attained may be studied in series. 
Did the first constructors of an arch, one wonders, derive the idea of laying stones with progressively narrowed bases together from the backbones of the animals which had been killed for their food? It is usual to talk about the vertebral column, but we might just as well call the spine a series of four arches, with successive narrowing and broadening of the anterior and posterior surfaces of the individual vertebrae and their connecting discs to form them.

What wonder is it if, with all the stresses of growth, of gradual assumption of the erect posture and of the carrying of weights additional to that of the head and body itself, either the curves of the spine or the joints of the spine with the limbs sometimes come short of perfection or lose their proper relations during later life? Some spinal defects are congenital (Law, 1953), some are due to disease, but most are due to postural faults or overloading, and thus are preventable, by proper care of the infant, the child, the adolescent and the worker in industry.

Law, A. (1953). "Vertebral Column-Injuries and Diseases." In British Encyclopaedia of Medical Practice, 2nd edition, p. 610. London: Butterworth.

\section{FOR SALE}

\section{PRIVATE PRACTICE.}

For Sale, Southern Rhodesia-Thriving Private Practice established 1925. Audits available. Big opportunity for energetic Physiotherapist. Two attractive and fully equipped treatment rooms and office situated centre of town in same buildings as ten other Doctors.

Owner retiring for domestic reasons. Part Payment considered.

Apply: P.O. 11, Physiotherapy DePT.,

General Hospital, Johannesburg.

\section{FOR SALE.}

One Faradic Battery, One Galvanic and Sinusoidal Machine, Two Infra-red Lamps and One Short Wave Diathermy Machine, all portable. Also One Hyfricator.

Write:-P. 012, Physiotherapy Department, General Hospital, Johannesburg, or 'phone 6-4967 (Cape Town).

GOOD PHYSIOTHERAPY PRATICE FOR SALE, CAPE TOWN. Available March 1 st or earlier. Any reasonable offer considered. For particulars-write: P. 013, Physiotherapy Department, General Hospital, JOHANNESBURG.

PHYSIOTHERAPIST urgently required for Nursing Home in Cape Town. Experienced with chest and orthopaedic conditions if possible.

Salary approx. $£ 47$ p.m. plus free lunch and tea. Apply:-P. 014, Physiotherapy Department, General Hospital, JOHANNESBURG.

\section{BOOK REVIEW}

The Principles of Exercise Therapy by M. Dena Gardiner, M.C.S.P., 260 p.p., 193 Figs., Published by G, Bell \& Sons, Ltd., York House, Portugal Street, London, W.C.2. Price 21s. net.

This is a book which physiotherapists have needed for years. Miss Gardiner is most qualified to write a book of this nature, since she has the Diploma of Bedford Physical Training College and is a Physiotherapy teacher.

The principles underlying movement of joints and muscles are clearly and fully explained. We are then given detailed techniques for mobilising joints and strengthening muscles. Although most of the text refers to active exercises, as naturally this forms the largest part of exercise therapy, the uses of static muscle work and of passive exercises are explained fully. Every joint in the body has specific movements described for it, both for mobilizng and strengthening.

The text is profusely illustrated with excellent clear diagrams. The clarity of the text is striking, and includes a very useful chapter on instruction of the patient.

This is quite the best of the very few books published on this important subject, and it must be recommended not only to students but to physiotherapists and everyone interested in this vital aspect of our work.

L.D.

Living WITh a Disability by Howard A. Rusk, M.D. and Eugene J. Tayor, published by The Blakiston Company Inc., Garden City, New York. Price \$3.50.

Howard A. Rusk and Eugene J. Taylor, respectively Director and Assistant Professor of the Institute of Physical Medicine and Rehabilitation of the New York University -Bellevue Medical Centre, have done a great service to all disabled persons by writing this book. They have collected together information about gadgets and devices for assisting these people in everyday activities so that they can become as independent as possible.

The book is extremely well illustrated by photographs, plans and diagrams of the various devices all with an accompanying description of them. Some would have to be made in Orthopaedic and Hospital workshops, but others are simple enough to be made at home.

This is primarily a book for the disabled person himself, but it is an invaluable asset to any physiotherapist, since it is essentially one of our important aims that we help disabled people to become as self sufficient as they can.

Included in the book is a very useful chart listing various daily activities whereby one can access a patient's disabilities. It would of course also act as a useful incentive and form of encouragement for the patient to be able to strike out his own particular disabilities as he learns to master them.

"Living With a Disability" was sent to us by the National Foundation for Infantile Paralysis and we are grateful to the Foundation for introducing to us such a well planned, useful and attractively produced book.

L.D. 